Article

\title{
Potential Climate Change risks to meeting Zimbabwe's NDC Goals - And how to become resilient
}

\author{
Mark Howells ${ }^{1 \& 2 *}$, Brent Boehlert ${ }^{3 \& 4}$, and Pablo César Benitez ${ }^{5}$ \\ 1 Imperial College London, Center for Environmental Policy. London, UK; \\ 2 Loughborough University, Department of Geography. Loughborough, UK; \\ 3 MIT, Joint Program on the Science and Policy of Global Change. Cambridge, USA; \\ BBoehlert@indecon.com \\ 4 Industrial Economics, Incorporated. Cambridge, USA; \\ 5 World Bank Group. Washington, DC, USA; pbenitez@worldbank.org \\ * Correspondence: M.I.Howells@lboro.ac.uk
}

\begin{abstract}
Zimbabwe has ambitious and laudable GHG mitigation targets. Compared to a coal based future emissions reductions by $33 \%$ per capita by 2030 are targeted, by implementing a set of identified nationally determined contributions (NDCs). If historical climate conditions continue, it can do this at low or negative cost.

However, anticipated conditions may not continue, and of the planned emissions reductions in the NDCs, $88 \%$ would come from the expansion of hydropower, which is driven by rainfall. If climate change causes the extreme droughts witnessed in recent years to become more frequent, embarking on Zimbabwe's NDC future (underpinned by its official system development plan) may be expensive and further cripple the economy. Note that the economy is already being strangled by constrained power supplies due to unusually dry conditions in the Zambezi river basin.
\end{abstract}

If the NDC Future is pursued, but the climate becomes drier, proactive efforts might be made to overcome the power shortages. However, this may result in a rapid ramp up of greenhouse gas emissions if the country turns to coal to reinforce its system and increase its resilience against hydropower vulnerability and the costs that would otherwise ensue.

If the country were to keep its NDC investments and supplement them with more aggressive deployment of clean adaptation options, strongly positive outcomes appear possible. Specifically, this would require increased deployment of renewable energy technologies, a restructured power market, and deep increases in energy efficiency investments. In so doing, the country would not only exceed its NDC targets, but also reduce costs in a manner that is climate resilient.

This would not remove the country's need for hydropower and some level of coal reliance. However, it will introduce requirements to ensure flexibility in both hydropower and coal power production. For hydropower, power stations will need to provide and be recompensed for providing 'balancing services', that is, storing water and producing electricity when the wind is not blowing, nor sun shining. In order to ensure continuous output from mines, it may require intelligent stockpiling combined with dynamic forecasting. This would apply not only to production in Zimbabwe, but potentially for neighboring countries. Doing so would allow 
predictable mining activities, but allow electricity systems to absorb low cost, low carbon hydropower at high rainfall periods.

To make the NDCs resilient via clean adaptation, strong institutional restructuring is required. However, internalizing those costs and moving to advanced market structures and business cases may strain the capacity of current institutions.

Keywords: Energy Modelling; Climate Change; Climate Resilience; OSeMOSYS; Integrated Assessment Modelling; Nationally Determined Contributions (NDCs); Renewable Energy Integration

\section{Introduction}

Zimbabwe's electricity system is both carbon intensive and highly rainfall dependent. In 2017 the International Energy Agency (IEA) estimated production was $46 \%$ coal and $54 \%$ hydropower (IEA 2018a). Considerably more electricity generation will be needed in the future to meet the needs of a growing population and planned economic expansion. There is potential for the system to meet increasing demand with continued use of coal. Coal is reliable, low cost, locally available, and increasing local coal mining provides local jobs. However, this electricity development trajectory directly conflicts with meeting the country's Nationally Determined Contributions (NDCs), in which Zimbabwe aims to reduce emissions by 33\% per capita by 2030, compared to a coal-based future (GoZ 2017).

The electricity sector and hydropower are a central focus of the country's NDCs: approximately $88 \%$ of the emissions reduction is expected to come from increased production of hydroelectricity (Table 1; UNFCCC 2017). This is consistent with the country's most recent System Development Plan (SDP; ZETDC 2017), which was issued in 2017 and then carried through as a nationally determined contributor to lower emissions.

Table 1: A summary of the measures as reported in the NDCs are provided below. 


\begin{tabular}{|l|l|l|l|}
\hline & Project & $\begin{array}{l}\mathrm{GgCO}_{2} \text { eq } \\
\text { in } 2030\end{array}$ & $\begin{array}{l}\text { Indicative cost } \\
\text { (US\$ mil) }\end{array}$ \\
\hline 1 & Ethanol blending & 202 & 100 \\
\hline 2 & Solar water heaters & 179 & 1230 \\
\hline 3 & Energy efficiency improvement & 1278 & 60 \\
\hline 4 & Increasing hydro in our energy mix & 15316 & 5000 \\
\hline 5 & Refurbishment and Electrification of the rail system & 341 & 1,106 \\
\hline & Sub Total 1 & $\mathbf{1 7 ~ 3 1 6}$ & $\mathbf{7 2 4 6}$ \\
\hline
\end{tabular}

Other key mitigation actions include the following with the estimated costs:

\begin{tabular}{|l|l|l|}
\hline 6 & Coal-bed methane (CBM) power. & 1000 \\
\hline 7 & Solar powered off-grids & 3000 \\
\hline 8 & Integrated Waste Management & 500 \\
\hline 9 & Changing thermal power station technologies & 5000 \\
\hline 10 & Reviewing the Transport system & 37000 \\
\hline 11 & REDD+ implementation & 1000 \\
\hline 12 & Sustainable Energy Alternatives of curing tobacco & 1050 \\
\hline & Sub Total 2 & $\mathbf{4 8 5 5 0}$ \\
\hline & TOTAL FOR MITIGATION & $\mathbf{5 5 7 9 6}$ \\
\hline
\end{tabular}

Yet hydropower is highly dependent upon climate conditions. Were those conditions to become systematically drier under climate change, achieving the NDCs would be at risk. The devastating droughts Zimbabwe has been experiencing over the last five years - and the resulting electricity shortages due to production shortfalls at Kariba and elsewhere-appear to be occurring more frequently, and this trend of larger extremes is likely to continue based on climate change projections.

In this paper, we seek to evaluate the level of risk to the NDCs from climate change, and to evaluate options to enhance the resilience of the NDCs to ensure that emissions targets are met.

\section{Background: Zimbabwe's Energy Sector and Climate Change}

Zimbabwe is heavily reliant on its coal and water resources to produce electricity. The bulk of supply is produced at the Kariba Dam Hydroelectric Power Station (750 MW), at the Hwange Thermal Power Station (920 MW) and at three smaller coal-fired power stations, all of which are managed by the Zimbabwe Electricity Supply Authority (ZESA) subsidiary, the Zimbabwe Power Company (ZPC; GET 2019). Yet these coal power plants are old with low dependable capacities. Just under half of the thermal power capacity of $1378 \mathrm{MW}$ thermal power plant is operationally dependable (ZETDC 2017).

Table 2: Existing power plants installed and dependable capacity as reported by the System Development Plan (Source: ZETDC 2017) 


\begin{tabular}{|l|c|c|}
\hline PLANT & INSTALLED CAPACITY(MW) & CAPACITY (MW) \\
\hline Hwange (1-6) & 880 & 300 \\
Harare & 120 & 30 \\
Bulawayo & 120 & 20 \\
Munyati & 100 & 20 \\
Chisumbanje & 18.3 & 4 \\
Dema & 100 & 100 \\
\hline Total Thermal & 1378.3 & 674 \\
\hline Duru & 2.2 & 2.2 \\
Nyamingura & 1.1 & 1.1 \\
Pungwe A & 2.7 & 2.7 \\
Pungwe B & 15.3 & 15.3 \\
Pungwe C & 3.75 & 3.75 \\
Kariba & 750 & 385 \\
\hline Total Hydro & 775.05 & 410.05 \\
\hline Total Local Capacity & 2153.35 & 884 \\
\hline
\end{tabular}

The average solar insolation in Zimbabwe is $5.7 \mathrm{kWh} / \mathrm{m} 2 /$ day. There is an enormous potential for use of solar PV and solar water heaters that has not yet been exploited; at present only $1 \%$ of the technical potential for solar water heaters has been exploited (Energypedia 2019). There are significant wind potentials with 12,137 TWh, 1,000 TWh, and $47.3 \mathrm{TWh}$ potential per year at load factors of more than $20 \%, 30 \%$ and $40 \%$, respectively (IRENA 2014).

However, without batteries, large quantities of wind and solar produce electricity intermittently. This is in a manner that can be difficult for the power system to absorb. It can result in a mismatch between when electricity is needed, such as in continuous mining operations, and when it is produced or unavailable, such as on a wind-still summer night. Despite this, there exists significant deployment potential.

One option to overcome this challenge is to store water (rather than electricity) in reservoirs and generate hydropower to fill the intermittent power gaps. This strategy also requires far less water than using hydropower continuously to supply baseload power. Similarly, coal might be stored, or stockpiled to do the same. Still there are limits to this approach. In several instances, up to $50 \%$ of the power generated in a country can be delivered from intermittent sources, but only if the rest of the system can be set up to balance deficits and curtail or eject the excess power through interconnectors. Though care must be taken to ensure that traditional power plants can ramp production outputs fast enough to maintain a stable system.

Another option is energy imports. Zimbabwe is a core member of the Southern African Power Pool (SAPP; SAPP 2019a), and is a net power importer. SAPP generation is dominated by coal (from South Africa) and hydropower elsewhere (SAPP 2019b). Zimbabwe's hydropower generation is dependent on the Zambezi river basin, as is hydropower generation from its neighbors to the north. Consequently, when there is a regional water shortage, there is a regional reduction in generation (OPM 2019). Further, coal-fired generation is a cornerstone of SAPP production. As coal requires mines, and those mines are developed in a manner to reduce risk, long term coal purchase-production agreements are often in place. Thus, were there a need, ramping coal mine production up or down to accommodate regional fluctuations in hydropower production is difficult. 
There is also significant potential for the introduction of energy efficient policies and measures (PAMs) - to reduce the quantity of electricity required per unit of economic output. In neighboring South Africa between 10-20\% electricity use reductions are economically feasible. And, this is in a setting where the cost of power production is relatively low. At higher production costs larger saving are possible; accounting for the costs of energy not served, Zimbabwe's costs are significantly higher than those of South Africa. Further, this is a fast-moving space with new innovation, technology and business models being developed rapidly. In Zimbabwe, techno-economic potentials are thus likely very high.

\section{Electricity futures in Zimbabwe}

Were anticipated hydropower regimes realized, Zimbabwe's Nationally Determined Contributions (NDCs) investments would result in a low carbon and cost-effective future. Will that NDC future expose the country's economy or emissions trajectory to risks if the climate were to change?

In this section NDC investments are modelled. This is needed in order to illustrate emissions reductions, and thereafter to understand how meeting NDC targets might fare under a changed climate. To show the impact on emissions reductions, a hypothetical scenario is developed wherein the country meets its future energy needs with coal. The scenario developed after this incorporates large planned injections of hydropower with gas and renewables (solar). This is consistent with-and updates-the national System Development Plan. Finally, in the last scenario, efficiency gains documented in the NDCs are incorporated. In so doing, we develop a Fossil Future, SDP+, and NDC scenario. Under each scenario, the increase in demand is adapted from the demand projections of the System Development Plan. In the NDC scenario, this demand is further reduced by modest energy efficiency measures.

\section{A Fossil Future}

A fossil future in Zimbabwe would involve the continued expansion of its coal-fired power plants. Like its water scarce neighbor in the South, dry cooling technology might be employed to ensure it resilience to low water availability (Ahjum 2018). While unlikely, a future based on coal provides this analysis (as it has done others) with a convenient backdrop against which lower carbon futures might be evaluated (Sims et al. 2003). It would involve investment in new coal power plans that would compensate for both increasing demand and the retirement of old power plants.

The SDP+ (System Development Plan)

The national system development plan (ZETDC 2017) and its preferred generation expansion scenario of the national SDP is summarized below. It relies on imports from the SAPP and a set of new power plants to be built. 
Table 3: Preferred System Development Plan (SDP) of Zimbabwe

\begin{tabular}{|l|l|l|l|l|}
\hline $\begin{array}{l}\text { Development } \\
\text { Sequence No. }\end{array}$ & Plant & $\begin{array}{l}\text { Capacity } \\
\text { MW }\end{array}$ & Year & $\begin{array}{l}\text { Investment } \\
\text { Costs (Inclusive } \\
\text { of Transmission } \\
\text { Connection) } \\
\text { USD Million }\end{array}$ \\
\hline 1. & $\begin{array}{l}\text { Average Power Imports (2017- } \\
\text { 2020) }\end{array}$ & 470 & $\begin{array}{l}\text { Ending } \\
2020\end{array}$ & 0 \\
\hline 2. & Kariba South Extension & 300 & 2018 & 412.00 \\
\hline 3. & Shilands Power & 210 & 2019 & 270.70 \\
\hline 4. & Gwanda Solar & 10 & 2019 & 17.70 \\
\hline 5. & Hwange 7 \& 8 & 600 & 2021 & 1439.00 \\
\hline 6. & $\begin{array}{l}\text { Hwange Stage 1\&2 Life } \\
\text { Extension }\end{array}$ & 880 & 2022 & 500.00 \\
\hline 7. & Batoka & 1200 & 2024 & 2600.00 \\
\hline 8. & Devil's Gorge & 1000 & 2031 & 2250.00 \\
\hline NPV (Scenario Objective Function) & & & $\mathbf{6 , 5 4 1 . 1 1 5}$ \\
\hline
\end{tabular}

Although recent, there are deviations from that plan - with some projects being late. Thus, aspects of the SDP are updated to develop an updated version thereof called the SDP+. The only adjustments made are in the timing, so allow for observed delays. Specifically:

KSE has been implemented (Bungane 2018).

Shilands - delayed (assumed fastest start up is 2022) (Choga 2018)

Gwanda - delayed with 2.5MW (i.e. 25\%) operational (assumed fastest start is 2021; Emmalogo555 2019).

Hwange 7 \& 8 - delayed to 2022 (ZPC 2019)

Hwange 1 \& 2 life extension delayed

Batoka - delayed (assumed fastest start is 2025; GE 2019)

Solar investments are assumed to continue as planned.

\section{The NDC future}

The SDP+ contains important elements of the countries NDCs (GoZ 2017), most important of which are the hydropower and renewables investments. Not included in the SDP+ are energy efficiency measures. The National NDC indicates that Energy Efficiency will result in emission reductions that are close to an assumed energy demand reduction of $5 \%$ by 2030. With the demand adjustment, a new scenario is developed and modelled, called the NDC future. Note that the only different between the SDP+ and NDC scenario is that the NDC scenario has 5\% lower energy demand. That in turn results in lower fossil fuel requirements and emissions.

Zimbabwe's energy future without considering climate change

Figure 1 presents future capacities, power generation and emissions from the electricity system for a fossil future, an updated system development plan (SDP+) and to meet its nationally determined contributions (NDC). Note the deep emissions reductions in the SDP+ scenario (indicated by the arrow in the second graphic in the last row). Extra reductions due to the reduced demand lead to a description of the NDC future scenario that is impressive in its potential (indicated by the arrow in 
the third graphic of the last row).1 Next we consider potential electricity futures in Zimbabwe to understand the potential of its NDCs and their vulnerability to climate change.

Figure 1: Zimbabwe's energy future without the threat of Climate Change

\begin{tabular}{|l|l|l|}
\hline Fossil Future & $\begin{array}{l}\text { Updated System } \\
\text { Development Plan (SDP+) }\end{array}$ & $\begin{array}{l}\text { Nationally Determined } \\
\text { Contributions (NDC) }\end{array}$ \\
\hline & &
\end{tabular}

\section{Capacity (Gigawatts)}
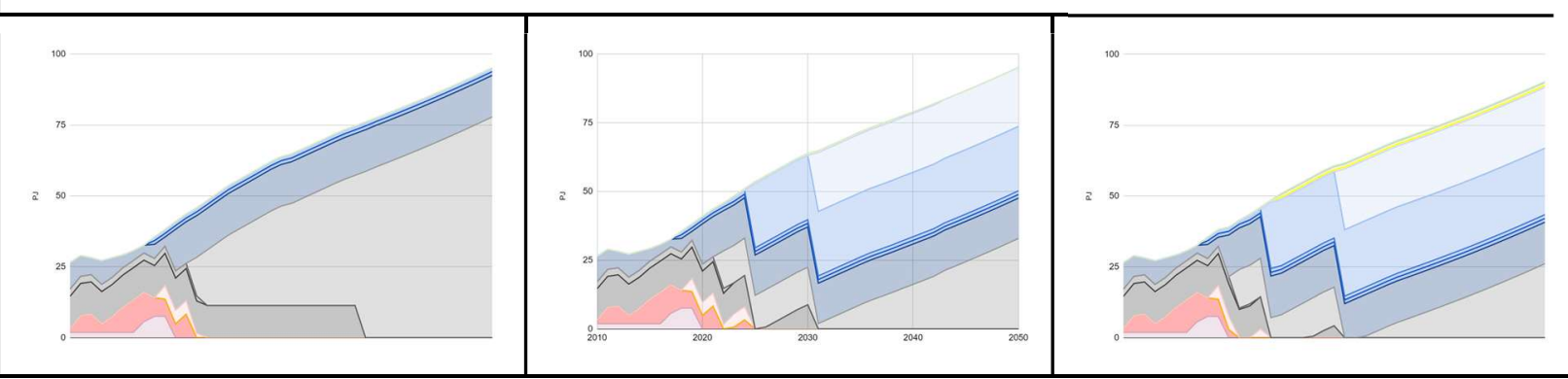

Wind (LF 30\%)

Wind (LF 20\%)

Solar PV (Homes)

Solar PV (Farm)

1. Hydro (Devils Gorge)

- Hydro (Gairezi)

Hydro (Batoka)

Hydro (KSE)

- Hydro (Tokwe)

- Hydro (Kariba)

Coal (New)

- Coal (Munics)

- Coal (Hwange)

Gas (New)

Energy efficiency

- Blackouts

Imports

\section{Generation (Petajoules)}
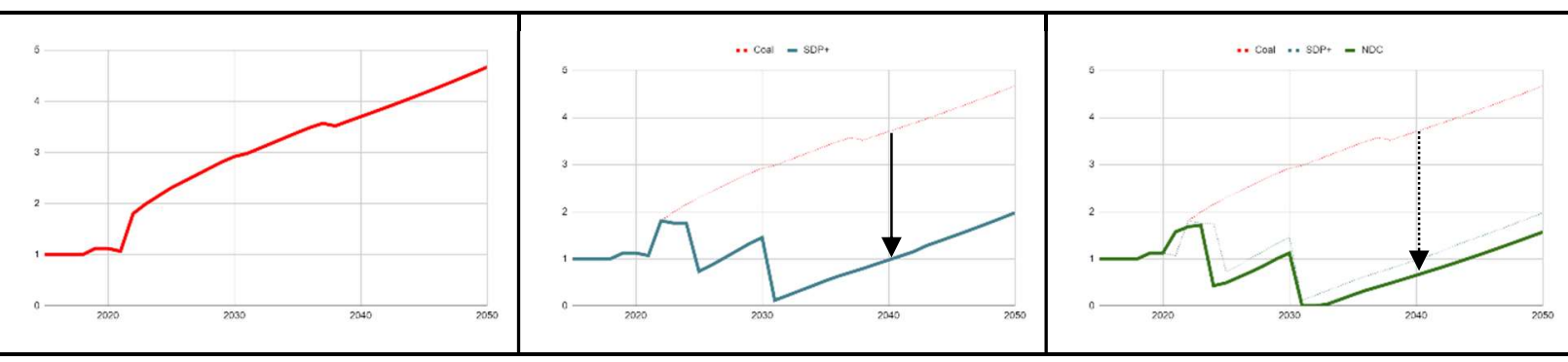

Emissions (relative to 2015 levels, i.e., 1 = 2015 and 2 = 2 x 2015)

\footnotetext{
${ }^{1}$ In this simulation, there are zero emissions for some years just after the full exploitation of the Devils George hydro station. Recall that this is (a) for the electricity sector only. And, note (b) that in those years no fossil fuelbased power is being generated at all. Also note that in the Fossil Future scenario, emissions will increase 5-fold between 2015 and 2050.
} 


\section{Climate Change Risks to NDCs}

The NDC future creates vulnerably to Zimbabwe's economy under climate change, and climate change threatens achievement of the NDCs.

The Zimbabwean electricity system is vulnerable to a changing climate. Power plants that use coal require water for cooling. In times of drought water is scarce and cooling difficult. Hydropower exposes the system to high levels of risk - as in times of drought there is little water to pass through the turbines. In this analysis, we investigate aspects of these risks and how to overcome them. Zimbabwe's neighbors in the Southern African Power Pool generate electricity from hydropower derived from the Zambezi basin. If there are regional water shortages, Zimbabwe will be unable to import to meet its own shortfalls - domestically or via imports. Further, households rely on biomass for cooking. But biomass demand is outstripping supply. During times of drought biomass growth slows or stops. And, this is reflected in slower supplies, which in turn accelerates deforestation. Thus, this too is vulnerable to climate change. 2 If cooking were undertaken with electricity it would be independent of biomass constraints. However, it would be subject to the vulnerabilities associated with the choice of power generation.

At present low rainfall is causing havoc in the region, and Zimbabwe in particular. Zimbabwe is currently facing food shortages and power cuts resulting from drought, and further food shortages are expected during 2020 (ReliefWeb 2018). Electricity supply to mines, farms and other key economic sectors is being cut due to extremely low elevations in Kariba reservoir and elsewhere. This cripples the economy (Silverstein 2019).

However, of interest is how the NDC infrastructure, if built out, will fare under future climates. We choose three futures from the publicly available climate projections used in the World Bank study, Enhancing the Climate Resilience of Africa's Infrastructure (ECRAI; Cervigni et al. 2015).3 The three selected futures present a relatively dry set of future from among the 65 CMIP5 scenarios, in order to focus on risks to achieving the NDCs. 4 Table 4 provides characteristics of the three scenarios, including projected change in precipitation, temperature, and potential evapotranspiration (PET) from the 1950 to 1999 baseline through the 2030s.

\footnotetext{
${ }^{2}$ Deforestation rates are high. According to the United Nations Environment Program (UNEP), Zimbabwe lost an annual average of 327,000 hectares of forests between 1990 and 2010 (IPS 2018). Much of this is due to tobacco curing.

${ }^{3}$ The ECRAI work, apart from passing peer-review, developed estimates of potential annual hydropower availability for a set of climate futures. It did so by using downscaled rainfall data to calculate projected runoff, which was then allocated to different uses across the Zambezi basin. Hydropower production data from the water systems model are fed into an energy systems model of Zimbabwe, which then runs an optimization routine to estimate an electric energy price trajectory for the reference case infrastructure.

${ }^{4} \mathrm{CMIP5}$ is the $5^{\text {th }}$ phase of the Combined Model Intercomparison Project, which includes the suite of climate model runs used in the $5^{\text {th }}$ IPCC assessment.
} 
Table 4. Selected climate scenarios

\begin{tabular}{l|c|c|c|c}
\multirow{2}{*}{ GCM } & Emissions & \multicolumn{3}{|c}{ Change through 2031-2040 } \\
\cline { 3 - 5 } & Scenario & Precip & T $\left({ }^{\circ} \mathrm{C}\right)$ & \multicolumn{1}{c}{ PET } \\
\hline GISS-E2-H_run1 & RCP 4.5 & $-32.5 \%$ & +2.13 & $+11.3 \%$ \\
MIROC-ESM-CHEM, & & & & \\
run1 & RCP 8.5 & $-17.3 \%$ & +2.06 & $+9.9 \%$ \\
bcc-csm1-1 & RCP 8.5 & $+2.9 \%$ & +2.60 & $+8.3 \%$
\end{tabular}

Figure 2 presents the electricity production in the NDC scenario under selected future climates. In all cases the country would experience significant economic damage. We see that due to projected long-term droughts under the first two scenarios, variable generation from hydropower in blue would fall dramatically, resulting in a large share of electricity not being served to the economy. That is illustrated by the red areas in the graphic. As all almost all formal economic activity requires electricity, unserved energy retards recovery and growth in an already fragile economy. To avoid these dire outcomes, it is likely that Zimbabwe would rely on coal-based generation or SAPP imports, thus increasing emissions and missing NDC targets.

Figure 2: Electricity production in the NDC future scenario under selected future climates (Petajoules)

\begin{tabular}{|c|c|c|c|}
\hline $\begin{array}{l}\text { GCM: GISS-E2-H, run } 1 \\
\text { RCP } 4.5 \\
\text { Downscaling: Princeton- } \\
\text { BCSD }\end{array}$ & $\begin{array}{l}\text { GCM: MIROC-ESM_CHEM, } \\
\text { run } 1 \\
\text { RCP } 8.5 \\
\text { Downscaling: Princeton- } \\
\text { BCSD }\end{array}$ & $\begin{array}{l}\text { GCM: bcc-csm1-1 } \\
\text { RCP } 8.5 \\
\text { Downscaling: UCT }\end{array}$ & 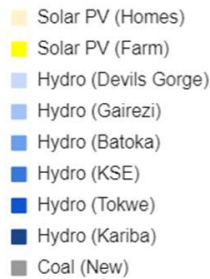 \\
\hline${ }_{100}^{+00}$ & 100 & ${ }^{100}$ & $\begin{array}{l}\text { - Coal (Hwange) } \\
\text { Gas (New) } \\
\text { Energy efficiency } \\
\text { - Blackouts } \\
\text { Imports }\end{array}$ \\
\hline
\end{tabular}

There are several options for responding to climate change. Two of these are not positive: one results in high economic damage and another in high emissions. A third option is possible that is both economically sensible and low carbon, but it will require aggressive policy action. 


\section{Responses to Climate Change}

Depending on how the country responds to that climate risk, there may be significant economic damage. There may be complete reversal of any emissions saved. Or, by rapid adoption of clean options - there may be improved economics, reduced emissions and climate resilience.

Assuming that the NDC investments will be pursued, we consider three actions that might be taken to build resilience to climate change.

Option 1: Inaction

The first option is to simply do nothing. While extreme, there may be circumstances that lead to this outcome. If the power system cannot meet demand with the investment as laid out in the NDC - it is assumed that any shortfall in generation will simply go unmet, or fossil-based resources from within or outside of Zimbabwe would be deployed. This case will be used contrast how the system might actively respond to a climate changed future, while keeping the NDC investments.

\section{Option 2: Coal Reinforcement}

In the next option we assume that planners foresee that electricity demand might go unmet unless new capacity is installed. They do not change the NDC investments, but supplement them. In this case, coal-fired power plants are constructed and operated. It is a convenient, conventional and safe option. Coal is inexpensive, there are local reserves and supply chains as well as operating procedures are well known. This proactive investment pathway would mean not meeting Zimbabwe's NDC targets.

\section{Option 3: Clean Adaptation}

In the clean adaptation scenario, it is assumed that there is a system transformation. All NDC investments are kept. However, larger quantities of solar and wind are allowed into the system generating a combined maximum of $50 \%$ of the alternative supplies at any one year. Deep energy efficiency cuts allow up to $20 \%$ of the energy to be reduced and any extra requirements to meet demand is met by new coal investment. Note that a $20 \%$ efficiency improvement is well within the range of international studies, and might be exceeded as modernization allows for a significant overhaul of energy-using infrastructure (IEA 2018b).

There are other options that require stronger political ambition. They include enhanced electricity trade between power pools - and hydro systems in different basins. An important example is the development of Grand Inga. This mega project in the Democratic republic of Congo requires deep coordination. However, rainfall in the basins are independent (as are dry periods) and the Congo River basin does not show a general drying. A general drying is a characteristic of the Zambezi river basin.

Zimbabwe's energy future considering responses to climate change 
Figure 3 indicates future capacities, power generation and emissions from the electricity system based on NDC investments under the GISS-E2-H climate future with adaptive action. As can be seen in the bottom left hand side of the graphic: inaction results in high economic damage. In fact the damage of inaction is more than double the cost to the economy of action. High levels of hydropower investments in the NDC scenario expose the system to water shortages that result from a drying climate. Sufficient electricity is not generated. The nationally determined investments become nationally economically disastrous due to the potential exposure to climate.

In both the Coal reinforcement and Clean adaptation there is a reduction in energy-not-served as new power plants are built and operated into the future. This reduces economic damage - and results in the supply of reliable electricity. Note however that in the short term there are power shortages, indicted by the red areas of the graphics between now and the early 2020s. This occurs in part due to an over dependence on hydropower generation; with low rainfall, there is little corrective action can be taken. In the medium term however, this is overcome with new investment.

Figure 3: NDCs at risk due to climate change (GISS-E2-H climate future)

\begin{tabular}{|l|l|l|}
\hline NDC with no adaptation & $\begin{array}{l}\text { NDC with coal/BAU } \\
\text { adaptation }\end{array}$ & NDC with clean adaptation \\
\hline & &
\end{tabular}

\section{Capacity (Gigawatts)}

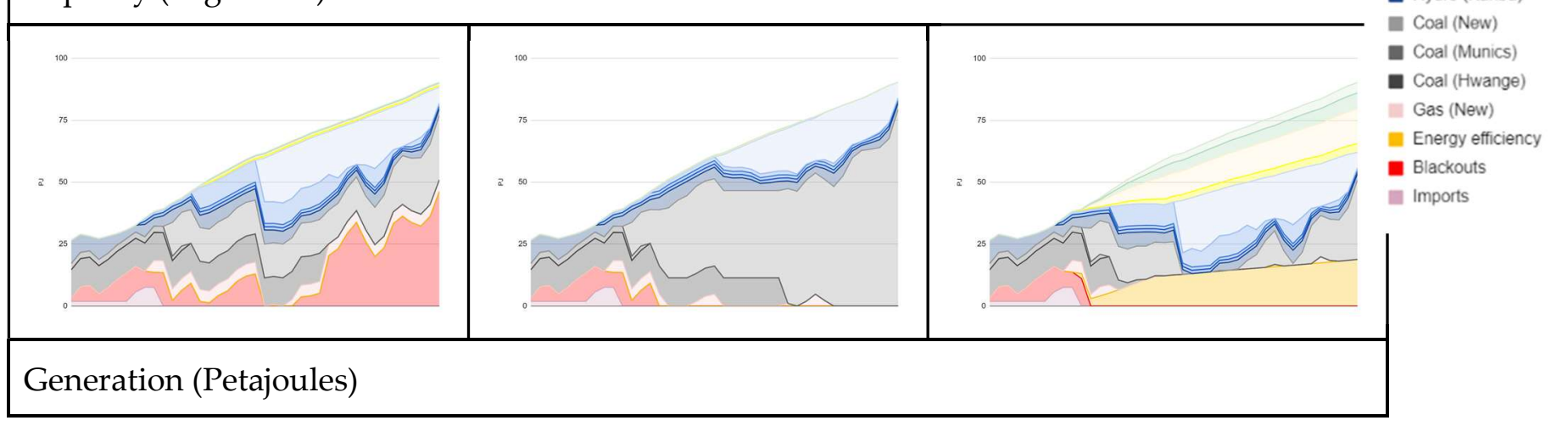




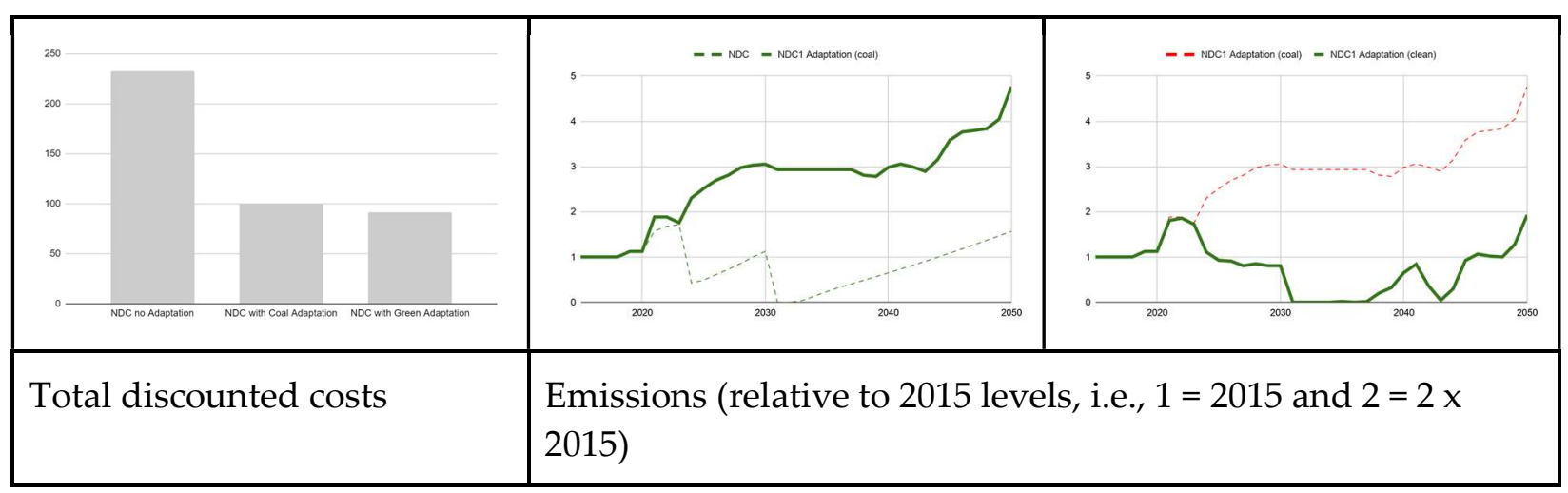

In the second column of the graphic, are the results for the Coal Reinforcement case. Important is the face that emissions, shown in the middle bottom graphic, skyrocket. The dashed line indicates the NDC target, were the climate is anticipated to be favorable. The solid line indicates a more than quadrupling of emissions by the end of the analysis period. This is almost as high as the Fossil Future scenario - with no NDC investment. And almost all NDC environmental gains are lost. However, as shown in the graphic on the bottom left, economic damage avoided is significant, and the total cost of the system to the economy is less than half of that when there is inaction.

The Clean Adaptation case is critically different. It takes advantage of renewables, high energy efficiency updates and balances the system with hydropower and coal. (In so doing it requires less hydropower and coal). Its emissions are lower than coal-reinforcement - and lower than the original NDC targets. Further, the extra renewable energy capacity costs are offset by lower fuel costs and reductions in demand due to energy efficiency. However, while the benefits are strong-so too is the level of: institutional requirements, new market structures and supporting measures, such as coal stock-piling.

Beyond the scope of this analysis, but critical to highlight is the role that regional power trade might play. As noted earlier with political will import from other basins will allow for burden sharing when supplies are limited from hydro in some basins to others with more reliable or independent supply. To give an example of the potential, consider the analysis of Taliotis et al (2016) that focuses on potential trade across Africa. In particular note how Zimbabwe (ZM) might benefit from the development and import from the Democratic republic of Congo (CD). These imports are shown in beige between the two countries. While Taliotis does not consider the impact of climatic change, the inference that trade might be a critical arrow in the quiver to tackle climate change, while exploiting electricity megaprojects, is clear. 


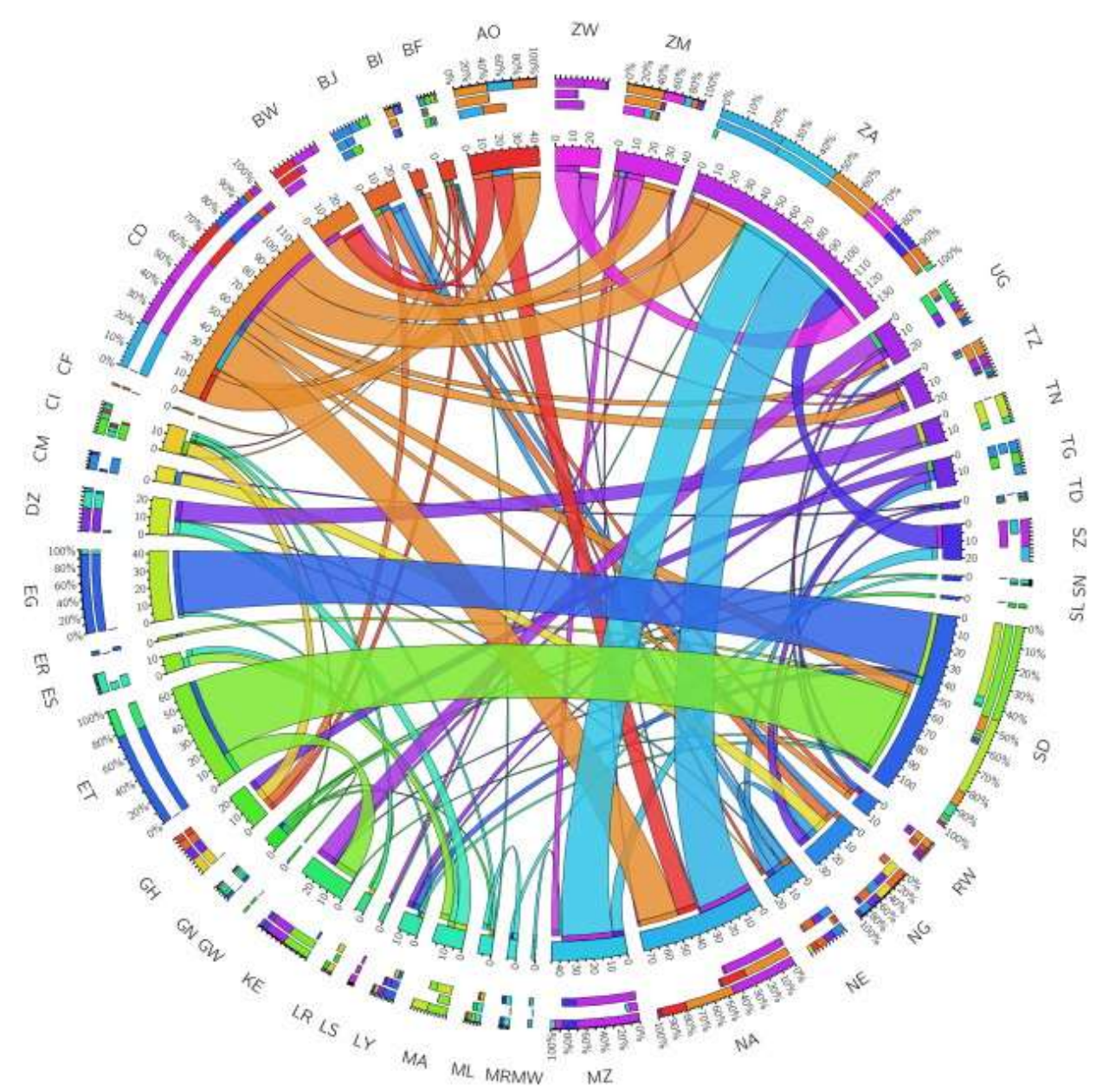

Figure 4. Inter-region power trade with unlimited power trade expansion

The key message is that Clean Adaptation with NDC's requires proactive action. At national level, this is is lower cost and lower emitting - securing all the NDC mitigation and more. Inaction is dangerous and will continue to damage the economy. A fossil future is secure and achievable, but is highly emitting.

\section{Findings and Limitations}

The analysis is a proof of concept piece, and thus is undertaken with several key limitations. These are appropriate given the setting of the analysis but are worth noting.

Climate proofing NDCs and exceeding mitigation targets is feasible, low carbon and potentially economically beneficial. This will require deep market adjustments that are discussed in detail later. However, aiming to meet the NDC targets with no climate resilience plan is economically dangerous. An NDC future is at risk under climate change, and with reactive coal-based reinforcement it will lead to all emissions gains lost. 
The analysis is a proof of concept piece and is undertaken with key limitations. While appropriate given the setting of this analysis, they are worth noting. Analytical limitations include:

- Limited climate runs. The goal was to uncover potential risks associated with following NDCs (with the underpinning System Development Plan). Thus we simply explore selected dry climate futures. They indicate risk. Future work would do well to evaluate a large ensemble of scenarios in order to capture a more comprehensive picture of the vulnerability, resilience and adaptivity of the country's NDC future and measure that might improve it.

- Limited scenario calibration. The calibration of the scenarios were necessarily limited. They drew from the best available existing studies. While more scenarios would be useful, in order to generate them, underlying work is required. That would include integrated assessment of water uses and constraints under different scenarios, in order to understand water availability for hydropower generation and balancing.

- Missing detail for policy formulation. Specific detail is missing in this analysis that would allow for more concrete policy formulation. That is deliberate, as such formulation should ideally be undertaken collectively. Its direction should also be informed by analysis of the granularity developed here.

- Structural changes will be required to realize the clean growth scenario mapped out together with its benefits. Some of those structural changes may be exceeded, some might not be realizable in the timeframes considered given local conditions and constraints. Though scenario limits are consistent with international experience elsewhere. Implementation constraints should be explored and fed back into the scenario definition.

- Technology characteristics are taken from international averages. These should be honed to be consistent with local conditions and realities. However, such data does not yet exist in the public domain. They include detailed and up-to-date: energy efficiency policies and measures by sector, with potentials and costs; an assessment of the operational regimes required to allow for the restructuring of conventional power generation to be used for balancing; and an estimate of the costs and performance changes associated with making the latter transition.

- Regional market design is not considered. Were hydropower regimes become very wet, would excess power from the SAPP be easily absorbed by South Africa? Would it be feasible to reduce coal-based generation until the subsequent dry spell?

- Pan-water basin analysis is not considered. This is particularly important as an interconnected Africa might draw from hydropower plants in different basins. Different basins have independent rainfall patterns. The likelihood of two droughts occurring simultaneously become lower.

- No assessment of ecosystem nor institutional requirements is made. Importantly these requirements should be unpacked into a set of action pathways with clearly delineated milestones that various actors need to reach. Without which systematic progress will be difficult. 


\section{Summary and Recommendations}

Without aggressive action Zimbabwe's NDC gains may be lost at high economic and environmental costs.

The NDCs and Zimbabwe's climate compatible growth can be made resilient. A key feature of the clean adaptation path required to get there is the combination of new renewables with hydropower. The model assumes a perfect market is adopted to this new investment and changes in operation occur. In reality the market is not perfect and will need to be restructured. The model indicates deep and achievable changes in the operation of hydropower occur. Those too, while demonstrably achievable, will require a change in traditional operation of hydropower as baseload generation only. And, equally important is the aggressive adoption of deep energy efficiency.

While the Clean Adaptation path promises strong benefits. It requires strong commitment, political will and restructure. To get there a pragmatic policy pathway and milestone approach is recommended (IAEA 2017).

A roadmap and milestone approach to implementation of Clean Adaptation policies and measures (PAMs) is critical. This begins with clear appraisal of specific PAMs including the regulatory framework and market rules required for successful deployment (both in terms of investment, and thereafter operation). It then moves to assess and identify the support required for implementation. That support is delineated with specific target milestones to be reached. It is aimed at providing actionable contextual intelligence.

- Appraisal, testing, evaluation and implementation of Clean Adaptation policies and measures (PAMs). The efficacy of the PAMs are to be assessed. That includes understanding their cost and benefit. The costs and benefits are to be pragmatically assessed ensuring that climate resilience and policy coherence (within and across sectors) is accounted for.

- Regulatory framework and market rules will be required for successful investment in and running of the PAMs identified. Note that these PAMs can include sharp departures from existing rules. An example is moving from an energy only to a balancing market.

- Supporting measures and decision making are then evaluated. Moving beyond regulations and market rules required, the national context and institutional ability to assimilate the PAMs are assessed. That national context will influence freedom to operate, market absorption, consumer behavior and societal acceptance of the technologies and business models associated with the PAM (REEEM 2019).

- Specific milestones are then developed to see through the delivery of the Clean Adaptation PAMs. Those include appropriate: national positioning and allegiances, safety culture development, business management structures, legal framework, 
regulatory framework, power system stability, institutional mandates, institutional resourcing, human capacity requirements etc.

A characteristic of planning in Zimbabwe should now include a step change in policy analysis generally so as to take into account, where pragmatic, climate vulnerability. This work demonstrates that billions of USD and economic damage (or livelihood) are at stake. While how this would propagate throughout government is beyond the scope of the recommendations here, specific suggestions for the planning the energyand electricity - sector are detailed. Key policy recommendations needed in the short term include the specific identification of PAMs to meet Clean Adaptation aspirations. That should necessarily be more granular, specific and substantial than at the level identified here.5 It should also determine the actually feasible levels of wind, solar and energy efficiency penetration, with appropriate sub-system cost curves. The modelling framework employed nationally to develop the SDP and NDCs needs to be updated to allow for a systematic changing of the planning approach to account for uncertainty. A specific advance would be running analysis across a large ensemble of potential climate futures - as well as other development uncertainties. In so doing infrastructure and objectives that are at risk can be identified via an emerging set of techniques. See recent work for South America and Africa undertaken by the WBG and others (Moksnes et al. 2019, Cervigni et al. 2015). This should be undertaken in order to identify optimal trade offs and pragmatic next steps in energy infrastructure deployment.

Further, policy coherence and within and across sectors is needed. For example, within the electricity sector no systematic integrated analysis between bulk power development (such as the hydropower and coal expansion) and off-grid expansion has been made. Integrating this analysis allows for gains as costs are harmonized and the co-benefits of off-grid electrification and reduced emissions can be simultaneously captured. Examples for such analysis can be found in Moksnes et al. (2017) and Mentis et al. (2017). This is especially the case as larger scale investment may be sensibly integrated than identified in the national NDC, and such analysis is becoming ubiquitously available. See for example the figure below from the Global Electrification Platform that houses hundreds of potential renewable energy off-grid electrification investment scenarios.6

Figure 5. A full RET offgrid base electrification scenario for Zimbabwe

\footnotetext{
${ }^{5}$ This would include for example, the development of technical interventions, policy measures to implement the intervention, the efficacy of those measures (relative to their technical potential), cost and benefit by sector and sub-sector, in enough detail so as to develop investment level information - see Hugues et al. (2002) for an example in South Africa.

${ }^{6}$ Global Electrification Platform Explorer. Global Electrification Platform Explorer https://electrifynow.energydata.info.
} 


\section{Zimbabwe}

Zimbabwe OnSSET vid
Global Electrification Platform

Explore least cost electrification strategies around the world.

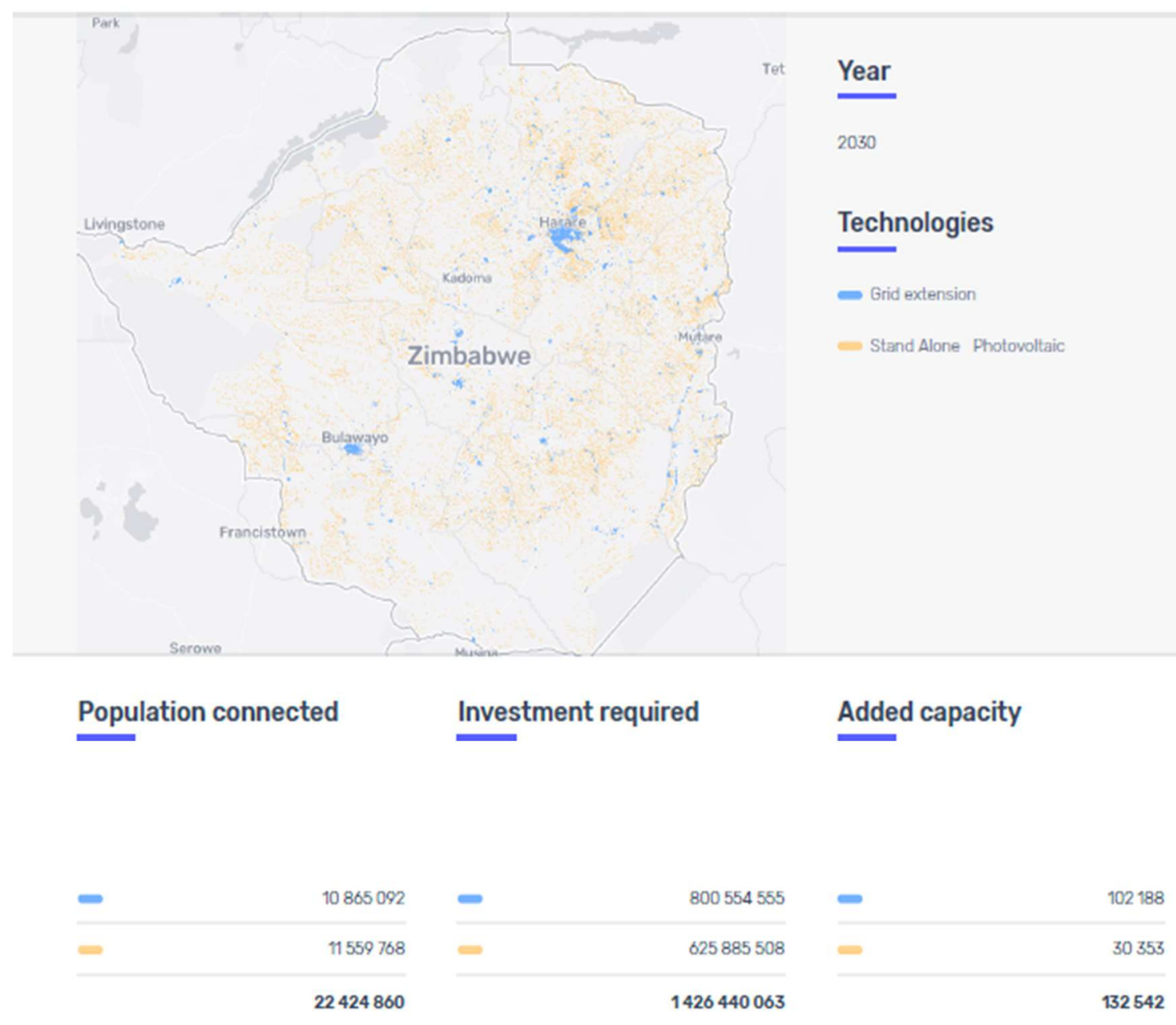

Across sectors there is clear need to ensure that there is harmonization between hydropower planning, water and agriculture policy. Approaches to improve inter-sector planning are on the increase. Pathbreaking work for Africa quoted earlier includes Sridharan et al. (2019). However, efforts need to be made to build local capacity to undertake such analysis routinely as part of the policy process. Work has shown that vulnerabilities can reinforce themselves. And, that reinforcing - and deep vulnerability - will go unnoticed without appropriate analysis (Howells and Rogner 2014). An example includes upstream water diversion and pumping for agriculture simultaneously reducing the potential for hydropower to generate electricity - while increasing the demand of electricity for pumping.

In order to develop the Clean Adaptation strategy outlined in this report, there will need to be changes to the regulatory framework and market rules that govern the power sector, coal-purchases, as well as energy efficiency markets. These are in keeping with trends developing globally. And, investigating the potential for the development of a balancing market 
is thus recommended. Such a market should allow conventional power plants to act (or be retrofitted to act) in a manner to allow the power system to absorb electricity from lower carbon intermittent sources such as wind and solar. While performing the balancing (rather than primarily producing power) they should be financially rewarded. When there is high concurrent production of wind, solar and hydropower production from coal-fired power plants will drop. However, due to the structure of coal purchase contracts and employment of miners, coal production is unlikely to stop. A special reserve fund should be developed to allow for the stockpiling of coal for when it is not needed. This will allow for continuous mining operations. The level of the stockpile should be sized to allow for its use to support coal-fired generation when it is needed, such that average continuous production of coal, equals average variable use of coal. Zimbabwe is part of the Southern African Power Pool (SAPP). At time of high wind, solar and hydropower production there may be cost benefits to export power into the SAPP. As with the domestic coal stockpiling described here, it may be that there are similar opportunities in neighboring countries. They might reduce local coalgeneration and consider developing a similar stockpiling initiative.

Energy efficiency and demand side measures are growing in importance and the subject of innovation. New business models and remote billing are allowing for the development of new energy efficiency and services need to be developed. A special focus should be the assessment of large-scale advanced energy efficiency adoption. However, the national context and potential to take advantage of these specific PAMs needs to be developed and account for new technology and business model's: freedom to operate (including supply chain constraints); the absorptive capacity of the local market; their compatibility with consumers and society etc.

The steps outlined above will be required while developing a pathway and milestone approach recommended. Without so doing Clean Adaptation Policies and Measures (PAMs) may be ineffective or have limited use. Without those PAMs the economy and environmental performance of Zimbabwe is at risk. However, if implemented sensibly there is clear potential for Zimbabwe's growth to be both low carbon and economic.

\section{Acknowledgements}

The financial support of Zimbabwe's Reconstruction Fund (ZIMREF) is gratefully acknowledged.

Howells acknowledges supplementary post project support from the Climate Compatible Growth Program (\#CCG) of the UK's Foreign Development and Commonwealth Office (FCDO). The views expressed in this paper do not necessarily reflect the UK government's official policies. 


\section{Appendix}

\section{Model description}

The model generator used in this analysis was the Open Source energy Modelling System (OSeMOSYS; Howells and Welsch 2010). This allows for ubiquitous Retrievability, Repeatability, Reconstructability, Interoperability and Auditability (u4RIA). It is widely used with accessible with accessible and with a large number of applications (Gardumi et al. 2018). It objective is to find the lowest cost feasible configuration of technologies and investments to meet an exogenously entered demand. A full set of documentation, code, and supporting material can be downloaded from www.OSeMOSYS.online.

\section{Data in Brief}

Note that all data used is public domain. It is also based on official national documents. This is helpful for dialogue. However it is thus limited, and should be updated as data is available.

The primary documents used to calibrate the analysis include the National System Development Plan ${ }^{3}$ and the International Energy Agency's Projected Costs of Generating Electricity (IAEA 2015).

\begin{tabular}{|l|l|l|l|l|l|}
\hline & $\begin{array}{l}\text { Capital Cost } \\
(\mathrm{USD} / \mathrm{kW})\end{array}$ & $\begin{array}{l}\text { Variable Cost } \\
(\mathrm{USD} / \mathrm{GJ})\end{array}$ & $\begin{array}{l}\text { Fixed Cost } \\
(\mathrm{USD} / \mathrm{kW})\end{array}$ & $\begin{array}{l}\text { Fuel Cost } \\
(\text { USD/GJ }\end{array}$ & Efficiency \\
\hline Coal & 2100 & $\begin{array}{l}\text { (Included in } \\
\text { FC) }\end{array}$ & 40 & 1 & $\begin{array}{l}33 \% \text { (old) } \\
40 \%(\mathrm{new})\end{array}$ \\
\hline Gas & 2100 & $\begin{array}{l}\text { (Included in } \\
\text { FC) }\end{array}$ & 40 & 6 & $54 \%$ \\
\hline Hydropower & 2500 & $\begin{array}{l}\text { (Included in } \\
\text { FC) }\end{array}$ & 20 & N/A & \\
\hline Wind & 2500 & $\begin{array}{l}\text { (Included in } \\
\text { FC) }\end{array}$ & 409 & N/A & \\
\hline Solar & 1500 & $\begin{array}{l}\text { (Included in } \\
\text { FC) }\end{array}$ & 289 & N/A & \\
\hline $\begin{array}{l}\text { Energy } \\
\text { Efficiency }\end{array}$ & 7500 & $\begin{array}{l}\text { (Included in } \\
\text { FC) }\end{array}$ & 10 & N/A & \\
\hline CUE & N/A & 1389 & N/A & N/A & \\
\hline
\end{tabular}


Electricity demand is taken directly from the SDP, and extended with a constant growth rate of $1.9 \%$ from 2035. Similarly anticipated hydropower capacity factors (without climate change) are as follows:

\begin{tabular}{|l|l|}
\hline Hydropower Station & $\begin{array}{l}\text { Anticipated } \\
\text { capacity factor }\end{array}$ \\
\hline Hydro (Kariba) & 0.62 \\
Hydro (Tokwe) & 0.68 \\
Hydro (KSE) & 0.14 \\
Hydro (Batoka) & 0.62 \\
Hydro (Gairezi) & 0.37 \\
Hydro (Devils Gorge) & 0.68 \\
\hline
\end{tabular}

\section{Scenario Tree}

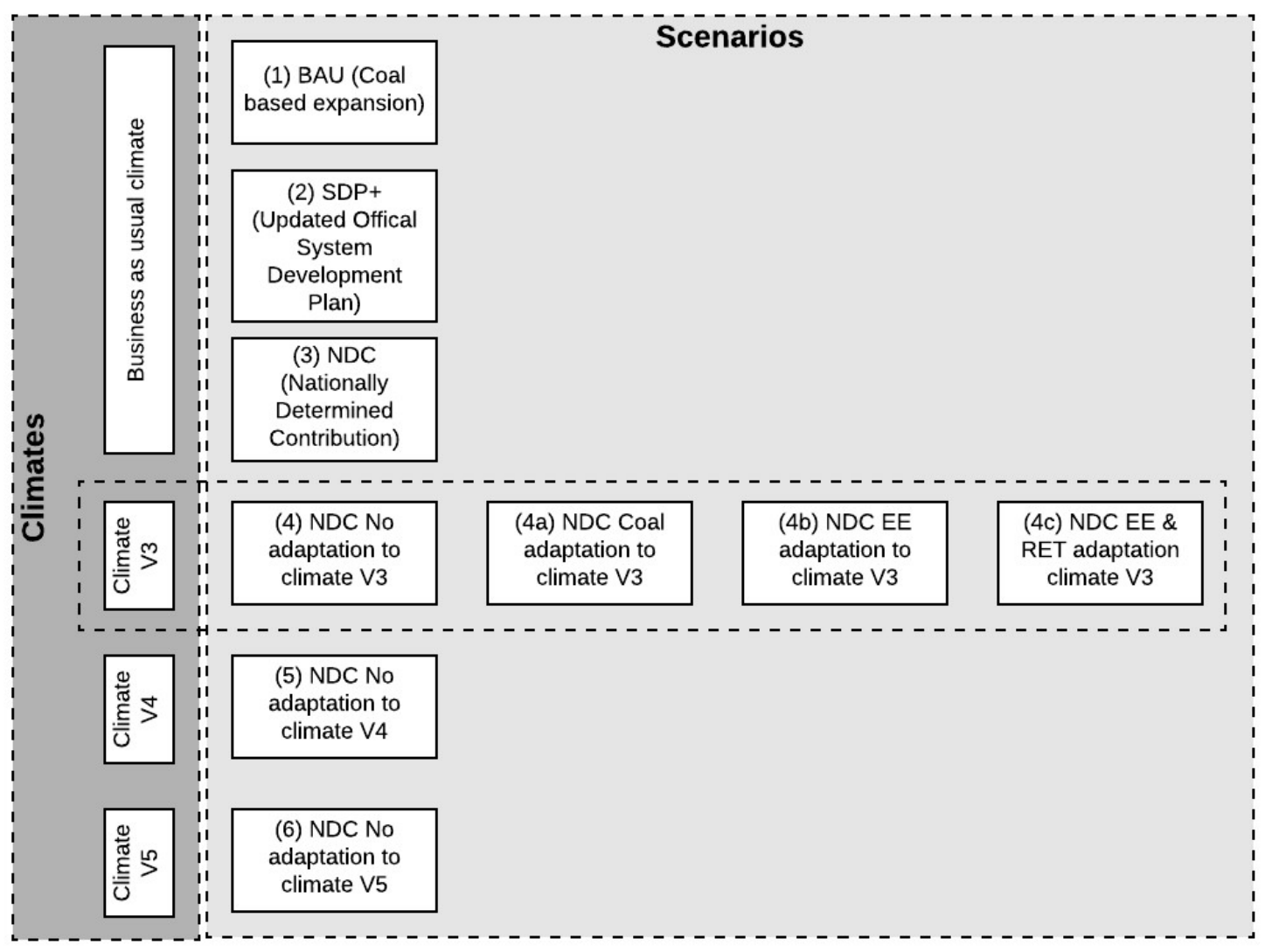




\begin{tabular}{|c|c|c|c|c|}
\hline $\begin{array}{c}\text { Sscenario } \\
\text { naming }\end{array}$ & GCM & Emissions & Vintage & Downscaling \\
\hline V5 & bcc-csm1-1-rcp85 & RCP 8.5 & CMIP5 & UCT \\
\hline V3 & GISS-E2-H_run1-rcp45 & RCP 4.5 & CMIP5 & Princeton-BCSD \\
\hline V1 & ips1_cm4-a2 & A2 & CMIP3 & Princeton-BCSD \\
\hline V2 & micro3_2_medres-a1b & A1B & CMIP3 & Princeton-BCSD \\
\hline V6 & $\begin{array}{c}\text { MIROC-ESM_CHEM- } \\
\text { rcp45 }\end{array}$ & RCP 4.5 & CMIP5 & UCT \\
\hline V4 & $\begin{array}{c}\text { MIROC-ESM_CHEM- } \\
\text { run1_rcp85 }\end{array}$ & RCP 8.5 & CMIP5 & Princeton-BCSD \\
\hline
\end{tabular}

Table 4.1: Licenses issued by ZERA

\begin{tabular}{|c|c|c|c|c|}
\hline & LICENSEE & TECHNOLOGY & CAPACITY & ESTIMATED \\
\hline & A. OPERATIONAL & & MW & \\
\hline 1 & Border Timbers* & Biomass- wood & 0.5 & \\
\hline 2 & Duru & mini-hydro & 2.2 & $2,969,604$ \\
\hline 3 & Green Fuel & Bagasse & 18.3 & \\
\hline 4 & Nyamingura & Mini-hydro & 1.1 & $6,769,053$ \\
\hline 5 & Pungwe $\mathrm{A}$ & Mini hydro & 2.75 & $4,474,576$ \\
\hline 6 & Hippo Valley Estates & bagasse (co-gen) & 33 & \\
\hline 7 & Triangle Estates & bagasse (co-gen) & 45 & $36,814,167$ \\
\hline 8 & Pungwe B Power Station & mini-hydro & 15.25 & $26,588,488$ \\
\hline \multirow[t]{3}{*}{9} & Pungwe C Power Station Pvt Ltd & mini-hydro & 3.72 & $7,000,000$ \\
\hline & SUB-TOTAL & & 121.82 & \\
\hline & B. NOT YET OPERATIONAL & & & \\
\hline 1 & Sengwa Power Station (RioZim) & Thermal (Coal- & 2400 & $4,400,000,000$ \\
\hline 2 & PER Lusulu (Pan African Energy & Thermal (Coal- & 2000 & $4,000,000,000$ \\
\hline 3 & Southern Energy & Thermal (Coal- & 600 & $1,100,000,000$ \\
\hline 4 & China Africa Sunlight Energy & Thermal (Coal- & 600 & $2,323,000,000$ \\
\hline 5 & Great Zimbabwe Hydro Power (Pvt) Ltd & Mini-hydro & 5 & $6,700,000$ \\
\hline 6 & Zimbabwe Power Company Gairezi & Mini-hydro & 30 & $128,012,352$ \\
\hline 7 & Manako Power (Pvt) Ltd & Mini-hydro & 2.5 & $13,000,000$ \\
\hline 8 & Kupinga Renewable Energy & Mini-hydro & 1.6 & $4,434,500$ \\
\hline 9 & Kariba Hydro Power (Pvt) Ltd & Hydro & 300 & $483,000,000$ \\
\hline 1 & GeoBase Klean Energy Africa & Solar & 250 & $240,000,000$ \\
\hline 1 & Hwange Power Station Stage III & Thermal (Coal- & 600 & $1,153,792,052$ \\
\hline 1 & Yellow Africa & Solar PV & 50 & $109,950,000$ \\
\hline 1 & H.T.Gen & Mini-hydro & 3.3 & $6,048,016$ \\
\hline 1 & Plum Solar & Solar PV & 5 & $6,723,000$ \\
\hline 1 & Immaculate Technologies & mini hydro & 1.7 & $2,962,000$ \\
\hline 1 & Shilands Enterprises & gas fired & 345 & $405,604,134$ \\
\hline 1 & De Green Rhino Energy & solar PV & 50 & $100,000,000$ \\
\hline 1 & Lueven Investments & Solar PV & 10 & $20,000,000$ \\
\hline 1 & Hauna Power Station Private Limited & mini hydro & 2.3 & $7,301,835$ \\
\hline 2 & Sinogy Power & Solar PV & 175 & $489,760,000$ \\
\hline 2 & Centragrid Private Limited & Solar PV & 25 & $50,334,049$ \\
\hline 2 & Utopia Power Company Private Limited & Solar PV & 15 & $25,100,000$ \\
\hline 2 & SolGas (Private) Limited & Solar PV & 5 & $8,423,750$ \\
\hline \multirow[t]{4}{*}{2} & Richaw Solar Tech Private Limited & Solar PV & 5 & $10,018,000$ \\
\hline & SUB TOTAL & & 7481.4 & \\
\hline & GRAND TOTAL & & 7603.22 & \\
\hline & C.CANCELLED LICENCES & & & \\
\hline 1 & Essar Africa Holdings (Pvt) Ltd ** & Thermal(Coal- & 600 & \\
\hline 2 & Essar (Captive power) ${ }^{* *}$ & Thermal(Coal- & 60 & \\
\hline \multirow[t]{2}{*}{3} & Rusitu Power Corporation*** & mini hydro & 0.75 & \\
\hline & & TOTAL & 660.75 & \\
\hline
\end{tabular}

Number of licensed projects $=33$

Number of state owned licensed projects $=3$ (highlighted in grey) 


\section{References}

1. Ahjum, F. et al. 2018. Development of a national water-energy system model with emphasis on the power sector for south africa. Environ. Prog. Sustain. Energy 37, 132-147..

2. Bungane, B. 2018. Zimbabwean power utility test run Kariba South extension project. ESI-Africa.com https://www.esiafrica.com/industry-sectors/business-and-markets/zimbabwean-power-utility-test-run-kariba-south-extensionproject/.

3. Cervigni, R., Liden, M. J. R., Neumann, J. L. \& Strzepek, K. M. 2015. Enhancing the climate resilience of Africa's infrastructure: the power and water 1-219 http://documents.worldbank.org/curated/en/857671468179354431/Enhancing-the-climate-resilience-of-Africasinfrastructure-the-power-and-water-sectors.

4. Choga, H. 2018. The reform of the Electricity Supply Industry in Zimbabwe and its impact on power sector investments since 2002. (University of Cape Town).

5. Emmalogo555. 2019. Zimbabwe's Gwanda solar plant project receives US \$14m. Construction Review Online https://constructionreviewonline.com/2019/11/zimbabwes-gwanda-solar-plant-project-receives-us-14m/.

6. Energypedia 2019. Zimbabwe Energy Situation - energypedia.info. https://energypedia.info/wiki/Zimbabwe_Energy_Situation.

7. Gardumi, F. et al. From the development of an open-source energy modelling tool to its application and the creation of communities of practice: The example of OSeMOSYS. Energy Strategy Rev. 20, 209-228 (2018).

8. GE. 2019. PowerChina Set to Build $\$ 4$ Billion Zambia-Zimbabwe Plant. IndustryWeek https://www.industryweek.com/leadership/article/22027792/ge-powerchina-set-to-build-4-billion-zambiazimbabweplant.

9. GET Invest. 2019. Energy Sector. https://www.get-invest.eu/market-information/zimbabwe/energy-sector/.

10. GoZ (Government $\quad$ of Zimbabwe). $2017 . \quad$ G. Zimbabwe https://www4.unfccc.int/sites/ndcstaging/PublishedDocuments/Zimbabwe\%20First/Zimbabwe\%20First\%20NDC.pdf.

11. Howells, M. \& Rogner, H. H. 2014. Water-energy nexus: Assessing integrated systems. Nat. Clim. Change 246-247.

12. Howells, M. \& Welsch, M. 2010. OSeMOSYS-The Open Source Energy Modelling System. in International Energy Workshop. Stockholm.

13. Hughes, A., Howells, M. \& Kenny, A. 2002. Energy efficiency baseline study. Capacity Build. Energy Effic. Renew. Energy CABEERE Rep. 4.

14. IAEA. 2015. Projected Costs of Generating Electricity. https://www.oecd-ilibrary.org/energy/projected-costs-ofgenerating-electricity_20798393.

15. IAEA. 2017. Milestones Approach. https://www.iaea.org/topics/infrastructure-development/milestones-approach.

16. IEA 2018a. Online Data Services. World Energy Balances. http://data.iea.org/payment/products/117-world-energybalances-2018-edition-coming-soon.aspx.

17. IEA. 2018b. Market Report Series: Energy Efficiency 2018 - Analysis. IEA https://www.iea.org/reports/energyefficiency-2018.

18. IPS. 2015. Zimbabwe's Famed Forests Could Soon Be Desert I Inter Press Service. http://www.ipsnews.net/2015/02/zimbabwes-famed-forests-could-soon-be-desert/.

19. IRENA (International Renewable Energy Agency). 2014. Estimating the Renewable Energy Potential in Africa: A GISbased approach. URL https://www.irena.org/publications/2014/Aug/Estimating-the-Renewable-Energy-Potential-inAfrica-A-GIS-based-approach (accessed 9.23.19).

20. Mentis, D. et al. Lighting the World: the first application of an open source, spatial electrification tool (OnSSET) on SubSaharan Africa. Environ. Res. Lett. 12, 085003 (2017).

21. Moksnes, N., Korkovelos, A., Mentis, D. \& Howells, M. 2017. Electrification pathways for Kenya-linking spatial electrification analysis and medium to long term energy planning. Environ. Res. Lett. 12, 095008.

22. Moksnes, N. et al. 2019. Determinants of energy futures-a scenario discovery method applied to cost and carbon emission futures for South American electricity infrastructure. Environ. Res. Commun. 1, 025001.

23. OPM (Oxford Policy Management). 2019. The impact of climate change on hydropower in Africa. Oxford Policy Management https://www.opml.co.uk/blog/the-impact-of-climate-change-on-hydropower-in-africa.

24. REEEM. 2019. Synthesis. https://reeempathways.org/synthesis.

25. ReliefWeb. 2018. Southern Africa: Drought - 2018-2020. https://reliefweb.int/disaster/dr-2018-000429-zwe.

26. SAPP (Southern African Power Pool). 2019a. http://www.sapp.co.zw/.

27. SAPP Statistics. 2019b. Southern African Power Pool. http://www.sapp.co.zw/sapp-statistics. 
28. Silverstein, K. 2019. For Southern Africa, Climate Change Is Real As Prolonged Droughts Are Creating Food Shortages. Forbes https://www.forbes.com/sites/kensilverstein/2019/11/07/for-southern-africa-climate-change-is-real-asprolonged-droughts-are-creating-food-shortages/.

29. Sims, R. E. H., Rogner, H.-H. \& Gregory, K. 2003. Carbon emission and mitigation cost comparisons between fossil fuel, nuclear and renewable energy resources for electricity generation. Energy Policy 31, 1315-1326.

30. Sridharan, V. et al. 2019. Resilience of the Eastern African electricity sector to climate driven changes in hydropower generation. Nat. Commun. 10, 1-9.

31. Taliotis, C., Shivakumar, A., Ramos, E., Howells, M., Mentis, D., Sridharan, V., Broad, O., Mofor, L., 2016. An indicative analysis of investment opportunities in the African electricity supply sector - Using TEMBA (The Electricity Model Base for Africa). Energy Sustain. Dev. 31, 50-66. https://doi.org/10.1016/j.esd.2015.12.001

32. UNFCCC. 2017. https://www4.unfccc.int/sites/NDCStaging/Pages/Party.aspx?party=ZWE.

33. ZPC (Zimbabwe Power Company). 2019. HWANGE $7 \quad \& \quad 8 \quad$ EXPANSION PROJECT. http://www.zpc.co.zw/projects/2/hwange-7-8-expansion-project.

34. ZETDC (Zimbabwe Electricity Transmission and Distribution Company). 2017. Z. System Development Plan. https://rise.esmap.org/data/files/library/zimbabwe/Cross\%20Cutting/CC\%202.pdf 